\title{
Four Side Views of Blue LED Patent Pricing
}

\author{
Nobuo TAKAHASHI ${ }^{\mathrm{a})}$
}

\begin{abstract}
The price of patents is limited by four sides of business management: (1) avoiding costs of the patent in question; (2) founder's profit of inventors, such as researchers and engineers, to bear risks involved in business establishment; (3) factors supporting competitive advantage identified in the resource-based view of strategic management; and (4) negative impact of big money for the researcher's invention. This tetragon of limitations bounds the price range of patents. This is illustrated by exemplifying the blue LED lawsuit case in Japan. This study presents the four side views on the differences between what companies pursue and what employee inventors pursue. However, these various differences make it possible to coexist and co-prosper between companies and inventors, otherwise they continue the tug-of-war forever on the one-dimensional monetary scale.
\end{abstract}

Keywords: licensing business, blue LED, founder's profit, resource-based view, work motivation

a) Graduate School of Economics, University of Tokyo, 7-3-1 Hongo, Bunkyo-ku, Tokyo, Japan, nobuta@e.u-tokyo.ac.jp

A part of this paper was originally published as Takahashi (2006b) in Japanese. 


\section{Introduction}

In Japan, Shūji Nakamura, one of the inventors of the blue Light Emitting Diode (LED), filed a lawsuit against his former employer Nichia Corporation over his inventor compensation in August 2001; the so-called "blue LED lawsuit." Consequently, several other lawsuits concerning inventor compensation were filed in Japan, paving the way for research into the evaluation of intellectual property rights, including patents (Goto \& Nagaoka, 2003; Goto \& Odagiri, 2003; Kikuchi, 2002; Okada, 2002; Takahashi, 2002).

In the blue LED lawsuit, the Tokyo District Court ruled in the first trial on January 30, 2004 that Nichia's monopoly profit from the invention of the blue LED was 120.8 billion yen. Setting Nakamura's contribution at $50 \%$, the court calculated his inventor compensation at a whopping 60.4 billion yen and ordered Nichia to pay Nakamura's claim of 20 billion yen in full. Many were surprised by this astronomical sum.

However, at the appeal hearing at the Tokyo High Court on January 11, 2005, a settlement was reached; Nichia was to pay Nakamura a sum of approximately 840 million yen, including inventor compensation of around 600 million yen. The blue LED inventor compensation made headlines, having been settled at just $1 \%$ of the 60.4 billion yen estimated by the Tokyo District Court.

Originally this court case only covered the "method of growing a semiconductor crystalline film of nitrogenous compounds" with Japanese Patent No. 2628404 (or "Patent 404," taking only the last three digits of the patent number). By contrast, this settlement amount of 600 million yen went beyond Patent 404 and included inventor compensation for all employee inventions attributable to Nakamura alone or to Nakamura and his co-inventors. The settlement covered 191 patents (including Patent 404) and four new designs for practical use registered in Japan, 112 patent applications 
pending approval by the Japan Patent Office, and corresponding foreign patents and inventions subject to foreign patent application and undisclosed know-how left unfiled for confidentiality. As a result, it is said that the maximum inventor compensation for Patent 404 alone was estimated at 10 million yen. This would mean that the assessment of its value was reduced to a mere $0.016 \%$ of the amount appearing in the Tokyo District Court ruling.

\section{Four Side Views of Patent Pricing}

Many people were amazed at the astronomical sum of 20 billion yen awarded by the district court. Many interested parties in both the industrial and academic world considered the sum to be far beyond all expectations. ${ }^{1}$ In fact, business practices had already developed and accepted market quotations for intellectual property rights in the licensing business (Nakano \& Takahashi, 2012; Saotome, 1987; Saotome \& Hashimoto, 2003; Wakumoto \& Nakano, 2005).

The monetary value of patents is quite distinct from the scientific value of an invention and depends on a company's strategic decision. Actually, even though an invention is outstanding from a scientific viewpoint, if the patent is, for instance, a new product that is to compete with the mainstay product that already boasts satisfactory sales and profits, then the company would shelve the patent and no production would take place; in other words, the patent has no money value. In other cases, commercialization costs may be excessive and the patent may not be commercialized by the company itself, but rather licensed out to another company at a relatively low price; most of the so-called straight licenses fall under such cases. It is impossible for a patent to have monetary value regardless of

1 At the time, there were doubts within Nichia regarding Nakamura's statement of single-handedly achieving everything (Fujii, 2002), although these doubts were not discussed outside the company. 
business options and strategic decision-making.

On the basis of these business management perspectives, the author of this paper submitted a position paper to the Tokyo High Court (Intellectual Property Division 3) on the blue LED lawsuit appeal hearing (Takahashi, 2005a). It argued that the price of patents is limited by the following four sides of business management:

(1) The costs to avoid the patent in question

(2)Founder's profit of inventors, such as researchers and engineers, to bear risks of business establishment

(3) Factors supporting competitive advantage, identified in the resource-based view of strategic management

(4) The negative impact of big money for the researcher's invention

This tetragon of these four sides bounds the price range of patents. The Tokyo High Court's settlement comprehends not only Patent 404 but also all of Nakamura's inventions, exuding a sense of licensing business; the amount of the cash sums by the court's ruling involved falls into the tetragon of limits.

\section{Avoiding Cost View}

In the business world, the monetary value of patents is determined by comparing the internal and external business options of a company. For instance, a company would decide to be licensed by another only if the costs to avoid the patent in question were higher than that of the license to use the patent. In other words, the licensing fee is conclusively determined to fall below the level of the cost to avoid the patent. This is the first side view; for example, the following two costs will be taken into account.

Research and development costs: A company examines the research and development $(R \& D)$ budget necessary for the company's $\mathrm{R} \& \mathrm{D}$ department to develop an alternative technology to avoid the 
patent within, for example, three years.

Litigation costs: In general, the company will consider the legal costs of submitting an appeal-for-invalidation claim about the patent, or the employees' workload for the lawsuit if a patent owner sues the company for infringement of the patent.

The company signs an agreement to buy or use the patent at the price or licensing fee only below the level of the costs to avoid the patent. Consequently, in case of high sales forecasts, the licensing fee at sum will exceed the avoidance costs, even if the licensing tariff rate is quite low. Actually, even a $1 \%$ fee of forecast sales is considered sufficient to influence the company's decision to avoid the patent; Patent 404 is a case in point. According to the district court ruling, Patent 404 is for products with high sales forecasts.

\section{Founder's Profit View}

Under the employment contract, inventor compensation for the employee's invention should be lower than the founder's profit that accrues when the inventor such as a researcher or an engineer bears risk on the business establishment. This is the second side view. This is because, if inventor compensation for the employee's invention exceeds the founder's profit, the researcher's lifelong salary plus inventor compensation is costlier to get patents than buying the founder's business; the company would no longer have to settle for an employment contract with a researcher.

If a researcher is also the founder of the company and succeeds in getting good patents, he/she could generate cash flow from the patents through one of the three choices: (i) commercialize the inventions in his/her own company, (ii) sell or license out the patents to another company, or (iii) sell a part or all of the stocks of his/her company, which owns the patents. In case of choice (i), he/she would be faced with the so-called "valley of death," the period of no cash flow 
from the commercialization, even if he/she had the technology at his/her disposal. However, most small companies in nascent stages are not ample in financial, human and material resources, or production facilities; they bear high risks and low probabilities of success in commercialization.

Further, choice (ii) is not a rational choice if he/she wants to maximize his/her founder's profit, because it greatly reduces the stock price in the Initial Public Offering (IPO) or valuation of the company's stock price. Even if the company only licensed out the patents, it could no longer use them exclusively. As a result, it is common practice for the founder to sell a part or all of the company's stocks along with the patents and make a profit on the transaction. Thus, choice (iii) maximizes the founder's profit. Therefore, in order to maximize founder's profit, it is usually sufficient to consider only the profit on the sale of stocks.

However, if the selling price presented by the founder is high, potential buyers would not be tempted and instead would (a) try to develop alternative technology; (b) get complementary patents to block new products from using that patent, thereby reducing its value and reaching a cross license agreement; or (c) submit an appeal-for-invalidation claim about that patent. In other words, the selling price presented by the founder should be lower than the costs incurred under (a)-(c).

In the case of Patent 404, the amount (billion yen) ruled by the district court is an extravagant selling price. All potential buyers assuredly choose one of the options, that is, from (a) to (c). That is, the selling price for the entire stock should fall below this amount.

However, an inventor or a founder cannot obtain the entire sale proceed of the stock, even if the sold company were solely owned by him/her. In case of an IPO, the inventor is normally not allowed to sell all of the stocks. This is because, when buying the company, a buyer wants to buy the company including the inventor and 
employees as well as their know-how and R\&D capabilities. The buyer generally would retain them for a period of 3-5 years at least. In this case, the inventor or founder needs to motivate the researchers and engineers to gain a commitment from them by wisely distributing a part of his founder's profit. However, if employees are given stock options as an incentive and they exercise them, this dilution will reduce the inventor's share.

In either condition, the inventor obtains only a part of the proceeds in the form of founder's profit from the sale of the entire stock. Moreover, both the proceeds and the founder's profit include the value of know-how and R\&D capabilities, not just the patents. Thus, we obtain the following inequality:

Proceeds from the sale of entire stock

$>$ Founder's profit > Price of patents

Similar to Williamson's (1975) transaction cost argument, a company would choose the employment contract only if its cost, including the inventor compensation, fell below the costs of various other options; for example, the buyer had far better sponsor starting up the researcher's business in exchange for a favorably low license fee, or had better beat down the stock price of his/her company. This is more economical than employing a researcher and paying a salary for life plus inventor compensation.

\section{Resource-Based View}

In the field of strategic management, an above-average profit is called "rent," and like economists, most researchers (e.g., Porter, 1980) have long sought a source for rent in monopoly of market. However, Demsetz (1973) found evidence that rent is not due to monopoly but factors unique to the company, and called it "Ricardian rent." Ricardian rent is generated by possessing resources that are 
scarce (Ricardo, 1817), or arises from the scarcity inherent in the supply of resources.

In 1984, two commemorable papers-Wernerfelt (1984) and Rumelt (1984)—were published, and a series of studies called the Resource-Based View (RBV) made its appearance. According to RBV, excess profits cannot be maintained with patents alone. The structure of RBV to sustain competitive advantage is (i) resource uniqueness/heterogeneity to generate Ricardian rent, and (ii) mechanisms to sustain the uniqueness/heterogeneity. Peteraf (1993) regarded points (b)-(d) of the below-listed mechanisms as essential:

(a) "Resource uniqueness/heterogeneity" that generates rent.

(b) Foresight or pure luck, through which a company gains resources without prior competition; these "ex ante limits to competition" allow the company to earn above average profits.

(c) Imperfect imitability and imperfect substitutability put "ex post limits to competition," which is necessary to sustain rent.

(d) If resources cannot be traded, this "imperfect mobility" limits a specific company to sustain the rent.

These four cornerstones characterize resources that enjoy a sustained competitive advantage and sustain above average profits. In fact, these four cornerstones (a) - (d) illustrate the case of Nichia's competitive advantage in the blue LED market.

First, Nichia generated excess sales and profits through the mass production of white LED. The explosive popularity of mobile phones with color liquid crystal displays, which was not anticipated when Patent 404 was invented, boosted demand for built-in white LED based inorganic luminescent materials (phosphors) in which Nichia has been strong traditionally. Thus, the development of the white LED is the key to Nichia's success. It had been commonly understood that a white light is made from the LEDs in three primary colors of light: red, blue and green. This is because in the case of light: red + 
blue + green $\rightarrow$ white. At the time, only blue LED did not exist among the three primary colors; therefore, the invention of the blue LED had been long awaited. However, Nichia's white LED is based on two other simple principles of the three primary colors of light: red + green $\rightarrow$ yellow; yellow + blue $\rightarrow$ white. Thus, combining blue LED and yellow-light-emitting luminescent material makes the white light, an unexpectedly neat and simple solution such as that by Columbus' egg story. This is a unique product (invention) that only a luminescent materials manufacturer could develop. According to this Nichia's method, white LED can be made using only one color (blue), not all the three colors. The development of the white LED can be seen as an impressive example of the first RBV cornerstone: (a) "resource uniqueness/heterogeneity" that generates rent.

Next, it is necessary to direct our attention to Nichia's foresight or luck. Nichia targeted its $R \& D$ investment on gallium nitride, while other competitors focused on zinc selenide. This led to the second RBV cornerstone: (b) "ex ante limits to competition" that allow the company to earn above average profits. At the time, it was said to be difficult to commercialize blue LED in the 20th century. Furthermore, in regard to (b), an important prior investment had been made in setting up a clean factory building for LED (Kishi \& Takahashi, 2010). Although an LED-making machine on casters is easy to move and make, a clean factory building in which such machines are installed requires a lengthy construction period. At the time of uncertain demand, Eiji Ogawa, the president of Nichia, decided to build a very large clean factory building by putting up his house as collateral for the construction fund. This prior investment enabled Nichia to catch up with explosively growing white LED demand and cover it monopolistically. Thus, through foresight or pure luck, Nichia gained "ex ante limits to competition" allowing itself to earn above average profits.

LED production is possible with patents as well as know-how, 
which is incorporated into the product design and production process. Imperfect imitability and imperfect substitutability of such know-how leads to the third RBV cornerstone (c) "ex post limits to competition" which is necessary to sustain the rent. Furthermore, Nichia's equipment to manufacture blue LED chips is self-made, that is, Nichia's blue LED chips machines are made by Nichia itself and cannot be traded in the market, this led to the fourth RBV cornerstone (d) "imperfect mobility."

In the case of Nichia, these four cornerstones made it possible to enjoy a sustained competitive advantage and above average profits. Therefore, we can calculate the value of patents by deducting the cost of these various factors (except for patents) from the rent. It is noteworthy that these cornerstones require the running expenses to support routine activities prior to R\&D. Penrose (1959/1980/1995) called such expenses "concealed investment," and a large part of the running expenses of big business have an investment character in their essence (Takahashi, in press).

\section{Money Impact View}

From the viewpoint of motivation, the rule of calculating inventor compensation should be designed in advance for motivating employees effectively to grapple with new technological problems and inventions; calculating inventor compensation in court after commercial success is completely meaningless.

Monetary rewards system alone does not work well as motivation tools. Inventor compensation should be integrated into a broader rewards system that includes intrinsic rewards under the condition of an employment contract. As Takahashi (2004) mentioned, the notion that raising pay increases the desire to work is superstition without scientific grounds. This can be observed in the familiar failures of performance-based pay systems in Japan from the second 
half of the 1990's to the first half of the 2000's.

Even before the experiments by Deci (1975), the psychologist famous for intrinsic motivation, and Vroom (1964), famous for his expectation theory based on extrinsic rewards, noted that "performance is not only a means to accomplish an objective but also indicative of the objective itself; regardless of externally mediated results on performance, it is suggested that the individual draws satisfaction from efficient execution and dissatisfaction from inefficient execution" (Vroom, 1964, pp. 266-267). In other words, he argued that an individual directly draws satisfaction from high performance and dissatisfaction from low performance, regardless of extrinsic rewards.

Nonetheless, monetary rewards need to be used with greatest caution because it often has a powerful negative impact (Takahashi, 2005 b, 2006a). In fact, paying inventor compensation of hundreds of million yen to just one researcher sharply increases the risk of destroying the teamwork of his R\&D team. Adequate results from an $R \& D$ team can be accomplished only if the company systematically assembles a team of a wide range of people, such as from the research director to the support craftsman in experiments. With such a team composition, it is extremely doubtful that the team would succeed even with just one team member missing. In such a team, it is impossible to measure one team member's contribution separately from the other team members'.

On the other hand, if just one team member monopolizes the total inventor compensation that amounts to several dozen of his teammates' annual income (several thousand times in case of the 60.4 billion yen estimated in the district court ruling), this would completely destroy the teamwork in the R\&D team. If the researcher in question wishes to continue his/her research work, rewards for invention within the employment system framework would probably need to be capped at tens of million of yen at most (i.e., within several 
times the annual income of rank-and-file employees). Thus, a company needs to carefully devise a plan that adequately compensates the inventor, such as by paying a lump sum at his retirement in addition to his retirement allowance.

Another negative impact of very high monetary rewards on the company is that the company would coolly abandon the commercialization of its own patents. This is because, in case of the invention succeeding, the company has to incur the burden of inventor compensation of hundreds of million or billion yen. In other cases, the patents will probably be shelved or licensed out to another company, which means that the employee inventor's dream to commercialize the invention fades away.

\section{Conclusion}

In this paper, four side views bound the price range of patents. This range corresponds to the settlement amount in the Tokyo High Court, not the Tokyo District Court ruling. The viewpoint taken in both this paper and in the position paper is reflected in the Tokyo High Court's "thinking on the settlement" as follows:

An inventor compensation for obtaining an employee invention by transfer should provide a satisfactory incentive for employees to invent. At the same time, an inventor compensation should allow a company to overcome a severe economic climate and international competition and foster continuous growth. It is reasonable to consider this amount as inherently different from the amount that partners in a company, bearing all sorts of risks, receive as profit in times of good or high performance.

The question remains of how many researchers are actually prepared to bear the risks themselves to make a fortune. Undoubtedly, the great majority of researchers believe that "a secure livelihood is important for devoting oneself to research." In other 
words, the nature of what companies pursue differs from what employee inventors pursue. Thus, these various differences make it possible to coexist and co-prosper between companies and inventor. Otherwise they continue the tug-of-war forever on the one-dimensional monetary scale. The four side views, or the tetragon of limitations discussed in this paper, highlight this point.

\section{References}

Deci, E. L. (1975). Intrinsic motivation. New York, NY: Plenum Press.

Demsetz, H. (1973). Industry structure, market rivalry, and public policy. Journal of Law and Economics, 16, 1-9.

Fujii, D. (2002). Inobeishon to guuzensei: Aoiro LED kaihatsu no jirei bunseki o tsuujite [Innovation and chance: A case analysis on blue LED development]. Organizational Science, 35(4), 68-80 (in Japanese).

Goto, A., \& Nagaoka, S. (Eds.). (2003). Chitekizaisan seido to inobeishon [Intellectual rights and innovation]. Tokyo, Japan: University of Tokyo Press (in Japanese).

Goto, A., \& Odagiri, H. (Eds.). (2003). Saiensu-gata sangyo [Science-based industries]. Tokyo, Japan: NTT Publishing (in Japanese).

Kikuchi, J. (2002). Keieishigen toshiteno chitekizaisanken no keizaikachihyoka [Economic valuation of intellectual property rights as management resources]. Organizational Science, 35(3), 26-34 (in Japanese).

Kishi, N., \& Takahashi, N. (2010). Licensing strategy of Japanese firms and competitive advantage. Annals of Business Administrative Science, 9, 1-12. doi: 10.7880/abas.9.1

Nakano, K., \& Takahashi, N. (2012). Licensing strategy of Japanese firms. In Y. Lecler, T. Yoshimoto, \& T. Fujimoto, (Eds.), The dynamics of regional innovation: Policy challenges in Europe and Japan (pp. 361-392). Singapore: World Scientific.

Okada, E. (2002). Kigyohyoka to chitekizaisan [Valuation of the firm and intellectual assets]. Tokyo, Japan: Zeimu Keiri Kyokai (in Japanese). 
Penrose, E. T. (1959/1980/1995). The theory of the growth of the firm. Oxford, UK: Basil Blackwell. 3rd ed. Oxford, UK: Oxford University Press.

Peteraf, M. A. (1993). The cornerstones of competitive advantage: A resource-based view. Strategic Management Journal, 14, 179-191.

Porter, M. E. (1980). Competitive strategy: Techniques for analyzing industries and competitors. New York, NY: Free Press.

Ricardo, D. (1817). On the principles of political economy and taxation. London, UK: John Murray.

Rumelt, R. P. (1984). Towards a strategic theory of the firm. In R. B. Lamb (Ed.), Competitive strategic management (pp. 556-570). Englewood Cliffs, NJ: Prentice-Hall.

Saotome, S. (1987). Raisenshingu bijinesu [Licensing business]. Tokyo, Japan: Japan Institute of Invention and Innovation (in Japanese).

Saotome, S., \& Hashimoto, M. (2003). Raisenshingu bijinesu [Licensing business]. Tokyo, Japan: Japan Institute of Invention and Innovation (in Japanese).

Takahashi, N. (2002). Bijinesumoderu tokkyo to makettingu [Business method patent and its marketing]. Annals of Japan Society of Business Administration, 72, 101-112 (in Japanese).

Takahashi, N. (2004). Kyomou no seikashugi: Nihongata nenkosei fukkatsu no susume [Performance-based pay system of false and fancy]. Tokyo, Japan: Nikkei Business (in Japanese).

Takahashi, N. (2005a). Sodaterukeiei no senryaku: Posutoseikashugi eno michi [Organization growing strategy: The way to a post-performance-based pay system]. Tokyo, Japan: Kodansha (in Japanese).

Takahashi, N. (2005b). Chitekizaisan to insentibu [Intellectual property and incentive]. Journal of the Intellectual Property Association of Japan, 2, 43-54 (in Japanese).

Takahashi, N. (2006a). Raisensu bijinesu to gijutsusha no hoshu [Licensing business and rewards to engineers]. Communications of the Operations Research Society of Japan, 51, 487-492 (in Japanese).

Takahashi, N. (2006b). Raisensu bijinesu gairon [Introduction to licensing business]. Akamon Management Review, 5, 581-613 (in Japanese). 
Takahashi, N. (in press). An essential service in Penrose's economies of growth. Annals of Business Administrative Science.

Vroom, V. H. (1964).Work and motivation. New York, NY: John Wiley \& Sons.

Wakumoto, Y., \& Nakano, K. (2005). Keieisenryaku toshiteno raisensu [License as management strategy]. Akamon Management Review, 4, 1-44 (in Japanese).

Wernerfelt, B. (1984). A resource-based view of the firm. Strategic Management Journal, 5, 171-180.

Williamson, O. E. (1975). Markets and hierarchies: Analysis and antitrust implications. New York, NY: Free Press. 